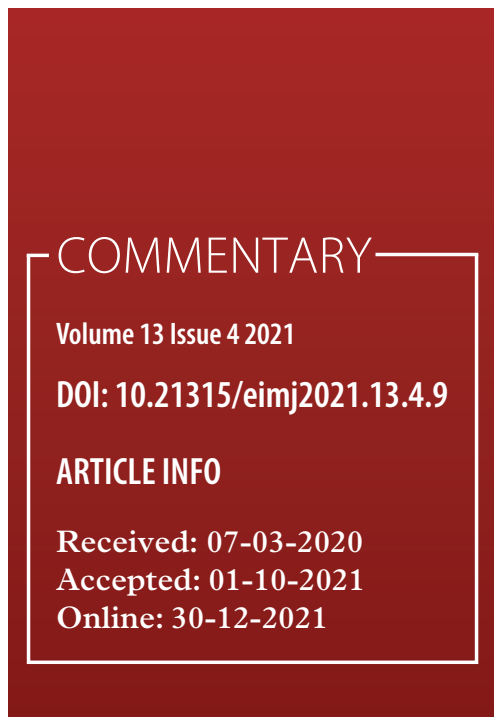

\title{
Challenges of e-Mentoring Medical Students During the COVID-19 Pandemic
}

Anna Alicia Simok', Mohamad Najib Mat $\mathrm{Pa}^{2}$, Ahmad Fuad Abdul

Rahim $^{2}$, Jamilah Al-Muhammady Mohammad²

${ }^{1}$ Department of Anatomy, School of Medical Sciences, Universiti Sains Malaysia, Kelantan, MALAYSIA

${ }^{2}$ Department of Medical Education, School of Medical Sciences, Universiti Sains Malaysia, Kelantan, MALAYSIA

To cite this article: Simok AA, Mat Pa MN, Abdul Rahim AF, Mohammad JAM. Challenges of e-mentoring medical students during the COVID-19 pandemic. Education in Medicine Journal. 2021;13(4):107-111. https://doi.org/10.21315/eimj2021.13.4.9

To link to this article: https://doi.org/10.21315/eimj2021.13.4.9

ABSTRACT

In the current pandemic scenario, the School of Medical Sciences, Universiti Sains Malaysia had adopted an e-mentoring system to help undergraduate medical students acclimatise to new subjects, improve academic performance and decrease attrition. The authors highlight the challenges of e-mentoring, including aspects of interpersonal dynamics, slow development of relationships in e-mentoring and the requirement of specific skills in technology for useful online mentoring, are the few challenges discussed. Some possible solutions were also shared. This article is beneficial to institutions implementing or planning to implement an e-mentoring system.

Keywords: e-Mentoring, Mentors, Mentees, Challenges, Pandemic

Jamilah Al-Muhammady Mohammad, Department of Medical Education, School of Medical Sciences, Health Campus, Universiti Sains Malaysia, 16150 Kubang Kerian, Kelantan, Malaysia

Email: jamilahkb@usm.my

\section{INTRODUCTION}

Students benefit from the knowledge and experience of mentors, including graduating on time (1). Mentoring in the School of Medical Sciences (SMS), Universiti Sains Malaysia (USM), was established in 2011. It helps undergraduate medical students acclimatise to new subjects, improves academic performance and decreases attrition (1). Volunteer faculty members are trained to mentor 8 to 10 students for two years in the pre-clinical phase or for three years in the clinical phase (2).
The COVID-19 pandemic has greatly affected higher education worldwide, including student mentoring systems (3). Like many other higher education institutions, the SMS converted the student group mentoring system into an e-mentoring system in response to the pandemic. E-mentoring combines mentoring with synchronous and asynchronous electronic communications to establish and maintain mentoring relationships between a senior person (mentor) and a less experienced person (mentee), independent of geographical or scheduling conflicts (4). 
When online distance learning is required, e-mentoring enables virtual engagement and benefits both mentors and mentees. This includes peer influence mentoring, which is an effective mentoring method (5). Mentees who better understand each other at the same level support each other academically and emotionally. E-mentoring also enables mentors to periodically guide their mentees and support them in keeping their study momentum going with self-discipline. Lastly, e-mentoring becomes a channel for moral support from mentors via virtual meetings without time and place restrictions (6). Research has established that mentees participating in e-mentoring perceive a greater level of support (1).

In this article, we share the challenges of e-mentoring in the SMS, USM, including aspects of interpersonal dynamics specific to computer-mediated communication (CMC) identified in the new e-mentoring norm. Possible solutions for the benefit of new mentors and mentees are also discussed.

\section{CHALLENGES OF E-MENTORING DURING A PANDEMIC}

The first challenge in using e-mentoring is preventing miscommunication. In the SMS, the e-mentoring platforms are Webex and Microsoft Teams, which allow synchronous meetings. Students tend to turn off their cameras to avoid internet lag, unintentionally blocking critical non-verbal facial signs, leading to misinterpretation and miscommunication (7). Due to this shortcoming, CMC is viewed as a "cold" medium that does not sustain relationships (8). In response, mentors in the SMS ask their mentees to turn on their cameras and microphones while answering questions or giving comments. Students in the University of New South Wales (UNSW) Sydney, Australia, think that over-utilisation of the internet impairs learning. To sustain relationships, mentors were strongly encouraged to interact with students during face-to-face (FTF) and online meetings (9).
In addition, improved CMC technology, for an example the Webex by Cisco allows communicators to perceive non-verbal communication better and infer its meaning (10).

The second challenge is the development of relationships in CMC. In the previous FTF mentoring system, mentor-mentee and mentee-mentee relationships progressed quickly from the "stranger phase" to a "trusted friend" phase. Even in the WhatsApp medium, mentors and mentees regularly discussed academic and personal issues. However, amongst the batch of mentees enrolled during the pandemic, relationship development was noticeably slower. The first Webex meetings between mentors and mentees were brief and conversations were stiff. The mentees answered questions only when asked by the mentor and they did not have any questions for their mentors or colleagues. After the online session, the mentors initiated conversations on WhatsApp, but the response was frigid. The relationship formation process in CMC is like FTF relationships, albeit slower, due to the decreased information exchange in CMC compared to FTF communication (11). The slower exchange of knowledge and growth of relationships is a concern in most mentor-mentee relationships, as mentors bring different engagement levels to their relationships (6). In CMC relationships, mentors can be disappointed with slow relationship growth. Use of more than one communication method (e.g., WhatsApp, Facebook and/or Instagram) by SMS mentors was encouraged to solve this problem. Some authors state that FTF interaction remains essential in mentoring programmes, as mentees do not know what to do during the initial CMC sessions until they have had their first FTF session (12).

Another challenge of e-mentoring is learning the specific skills needed to interact effectively online. Mentors and mentees who were new to Webex or Microsoft Teams had to familiarise themselves with these applications before commencing 
the e-mentoring sessions. Some mentees initially had difficulty entering the virtual room; the mentors needed to take quick action by inviting the mentees into the room. A minimum level of familiarity with synchronous meetings and other simple computer applications is a competency that online mentors and mentees need to master (13). Consequently, mentors and mentees in the SMS were consistently urged to improve their computer skills. In addition, a technical support team assisted mentors and mentees via training sessions, briefing sessions or video recordings. Similarly, in UNSW, mentors considered their unfamiliarity with Slack or Microsoft Teams a limitation (9) and underwent a training session upon implementing the e-mentoring programme.

Several incidents illustrate the fourth challenge. Just before an e-mentoring session, a computer microphone suddenly malfunctioned, delaying the session. In another session, the mentor's laptop suddenly restarted, forcing the mentor to exit the virtual meeting room. This risk of device failure is a difficulty that could unexpectedly occur in e-mentoring. These technical issues detract from the relationship's momentum and trigger contact lapses (14). Online relationships between mentors and mentees who experience regular computer malfunctions are less successful. Most mentors depend primarily on CMC during the COVID-19 pandemic and are affected by these problems (6). A related issue is a poor internet connection. The SMS technical support team was instrumental in assisting mentors when faced with this challenge. We found a few comparable papers concerning this issue $(6,14)$ but none in the pandemic e-mentoring literature.

Finally, the fifth challenge faced was an increase in responsibility as a mentor. USM, like other universities worldwide, adopted online learning and teaching involving the majority of students. In the comfort of their homes, students may struggle to keep focused and motivated (15). Distractions and temptations interrupt these students' study rhythms and intrinsic motivation. Some may even struggle emotionally, as online learning may be more tiring compared to FTF lectures. While attending an online session, parents may ask students to help with household chores, which may serve as an external stressor. As a result, students have difficulties focusing on and understanding the online lectures. To some, this may be frustrating.

Consequently, mentors now play a more significant role as counsellors to their small group of mentees. These students need to be counselled and motivated frequently and regularly. An institute in Hamburg, Germany, faced a similar situation and observed that medical students' study motivation decreased due to the pandemic. The authors pointed out that mentors play an essential role in addressing this problem (15). Mentors in SMS who were also medical lecturers found this challenging. Hence, having a support group of fellow mentors and a counselling training session are beneficial.

Notably, financial issues concerning internet data expenses did not pose a challenge during this pandemic. This could perhaps be explained by the government's provision of one gigabyte of free internet data per day, which significantly reduced the financial burden for online learning. Furthermore, e-mentoring does not take up much data, as interaction occurs mainly via WhatsApp and virtual meetings are held only once a month.

The challenges and their solutions are summarised in Table 1. A recent systematic review concluded that research on mentoring during the COVID-19 pandemic focused more on the mental challenges of students and academic support and less on the challenges faced in e-mentoring (16). 
Table 1: Challenges of e-mentoring and suggestions for institution to overcome the issues

\begin{tabular}{|c|c|}
\hline Challenges of e-mentoring & Suggestions for institution \\
\hline $\begin{array}{l}\text { Aspects of interpersonal dynamics of } \\
\text { CMC. }\end{array}$ & $\begin{array}{l}\text { Encourage mentees to on their video and microphone when } \\
\text { talking. } \\
\text { Allow mentees to use emoji and filter backgrounds. }\end{array}$ \\
\hline $\begin{array}{l}\text { Slow development of relationships in } \\
\text { CMC. }\end{array}$ & $\begin{array}{l}\text { Utilise a variety of communication apps (e.g., WhatsApp, } \\
\text { Facebook, Instagram). } \\
\text { Increase the frequency of the conversation. } \\
\text { Mentors to initiate the conversation. }\end{array}$ \\
\hline $\begin{array}{l}\text { The requirement of specific skills in } \\
\text { technology for effective e-mentoring } \\
\text { session. }\end{array}$ & $\begin{array}{l}\text { Continuous practice to improve computer skills. } \\
\text { Establish a technical support team to assist mentors and } \\
\text { mentees with these technical problems. } \\
\text { Provided training sessions, briefing sessions or video recordings } \\
\text { on new apps as guidance for mentors and mentees. }\end{array}$ \\
\hline $\begin{array}{l}\text { The risk of device failure during } \\
\text { e-mentoring session. }\end{array}$ & Establish and seek technical support team. \\
\hline $\begin{array}{l}\text { Additional responsibility as a mentor } \\
\text { (e.g., student counsellor). }\end{array}$ & $\begin{array}{l}\text { Establish a support group of fellow mentors. } \\
\text { Provide counselling training session. }\end{array}$ \\
\hline
\end{tabular}

\section{CONCLUSION}

Interpersonal dynamics and the slow development of relationships in CMC mentoring, the acquisition of specific computer-related skills for online mentoring, the risk of device failure during an online mentoring session and additional responsibility as a mentor are the challenges faced by mentors and mentees in the SMS, USM, during the pandemic. These challenges were addressed by appropriate preparation, training and preventive measures. We suggest future research on e-mentoring platforms or modules to optimise their efficiency.

\section{REFERENCES}

1. Tinoco-Giraldo H, Sánchez EMT, García-Peñalvo FJ. E-mentoring in higher education: a structured literature review and implications for future research. Sustainability (Switzerland). 2020;12(11):4344. https://doi.org/10.3390/ su12114344
2. Nor Mat MZ, Mohammad JAM, Yaacob NM. The USM mentoring inventory: a construct validity and reliability exercise. Education in Medicine Journal. 2019;11(2):15-26. https://doi.org/10.21315/ eimj2019.11.2.3

3. Schleicher A. The impact of COVID-19 on education: insights from education at a glance 2020 [Internet]. Paris: OECD; 2020 [cited 2020 December 15]. Available from: https:/www.oecd.org/education/theimpact-of-covid-19-on-education-insightseducation-at-a-glance-2020.pdf

4. Rowland KN. E-mentoring: an innovative twist to traditional mentoring. J Technol Manag Innov. 2012;7(1):228-37. https://doi. org/10.4067/S0718-27242012000100015

5. Carragher J, McGaughey J. The effectiveness of peer mentoring in promoting a positive transition to higher education for first-year undergraduate students: a mixedmethods systematic review protocol. Syst Rev. 2016;5(1):68. https://doi.org/10.1186/ s13643-016-0245-1 
6. Alemdag E, Erdem $M$. Designing an e-mentoring program for novice teachers in Turkey and investigating online interactions and program outcomes. Mentor Tutoring Partnersh Learn. 2017;25(2):123-50. https://doi.org/10.1080/13611267.2017.132 7394

7. Byron K. Carrying too heavy a load? The communication and miscommunication of emotion by email. Acad Manag Rev. 2008;33(2) https://doi.org/10.5465/ amr.2008.31193163

8. Sherblom JC. The computer-mediated communication (CMC) classroom: a challenge of medium, presence, interaction, identity, and relationship. Commun Educ. 2010;59(4):497-523. https://doi.org/10.1080 $/ 03634523.2010 .486440$

9. Cochran B, Polly P, Jones G, Rowe A. eMentoring a community of early career researchers to support and enable research integrated learning and professional skills development for undergraduate medical science students 2021. https://doi. org/10.35542/osf.io/wz7s4

10. Venter E. Challenges for meaningful interpersonal communication in a digital era. HTS Theological Studies. 2019;75(1):a5339. https://doi.org/10.4102/ hts.v75i1.5339

11. Ruppel EK, Gross C, Stoll A, Peck BS, Allen M, Kim S-Y. Reflecting on connecting: meta-analysis of differences between computer-mediated and face-toface self-disclosure. J Comput Commun. 2017;22(1):18-34. https://doi.org/10.1111/ jcc4.12179
12. Heaton-Shrestha C, May S, Edirisingha P, Linsey T, Burke L. From face-to-face to e-mentoring: does the " $\mathrm{e}$ " add any value for mentors? J Educ. 2009;20(2):116-24

13. Schichtel M. Core-competence skills in e-mentoring for medical educators: a conceptual exploration. Med Teach. 2010;32(7):e248-62. https://doi.org/10.3109 /0142159X.2010.489126

14. Ensher EA, Heun C, Blanchard A. Online mentoring and computer-mediated communication: new directions in research. J Vocat Behav. 2003;63(2):264-88. https:// doi.org/10.1016/S0001-8791(03)00044-7

15. Guse J, Heinen I, Kurre J, Mohr S, Bergelt C. Perception of the study situation and mental burden during the COVID-19 pandemic among undergraduate medical students with and without mentoring. GMS J Med Educ. 2020;37(7):Doc72. https://doi. org/10.3205/zma001365

16. Ardekani A, Hosseini SA, Tabari P, Rahimian Z, Feili A, Amini $M$, et al. Student support systems for undergraduate medical students during the COVID-19 pandemic: a systematic narrative review of the literature. BMC Med Educ. 2021;21(1):352. https://doi.org/10.1186/ s12909-021-02791-9 